\title{
Argon laser treatment of senile retinoschisis
}

\author{
Y. YASSUR, R. FELDBERG, R. AXER-SIEGEL, B. SILVERSTON, R. MANOR, \\ AND I. BEN-SIRA \\ From the Department of Ophthalmology, Beilinson Medical Center, Petah Tiqva, and \\ Tel Aviv University Sackler School of Medicine, Israel
}

SUMMARY Fifty-seven eyes of 49 patients with senile retinoschisis were treated by argon laser photocoagulation and followed up for 3 to 6 years. In most of the treated eyes the retinoschisis either completely or partially collapsed and in none did the retinoschisis or loss of visual field progress further. No long-term complications due to the treatment were noted. In none of the treated eyes did retinal detachment develop. In view of this the indications at present for argon laser treatment in retinoschisis may be extended to include any case in which the retinoschisis progresses beyond the equator and visual field loss continues. This may prevent further visual field damage and other rare complications of slowly progressive retinoschisis and facilitate the many years' follow-up of elderly patients with retinoschisis who develop cataracts.

Senile, or degenerative, retinoschisis which is noted in adult life, is believed to be the end result of cystoid peripheral retinal degeneration. ${ }^{1-3}$ The disease was described as involving splitting of the retina through the anterior plexiform layer between the nuclei of the visual cells and the bipolars. ${ }^{1245}$ In a comprehensive study based on clinical and pathological observations Foss $^{6}$ and Straatsma and Foos ${ }^{7}$ differentiated between 'typical' or 'flat' and 'reticular' or 'bulbous' retinoschisis. The prevalence of the disease was report to be $0.7 \%$ of adult eyes in the typical retinoschisis and $0.95 \%$ of adult eyes in the reticular retinoschisis. $^{7}$

The process starts at the extreme periphery of the retina and spreads towards the posterior pole. ${ }^{89}$ Sometimes this process is multifocal, and there is no communication between the retinoschisis bullae. ${ }^{10}$

There is still a significant difference of opinion on the rate of progression and symptomatology of the disease, the importance of demarcation line, and the risk of retinal detachment. ${ }^{10}$ In most cases the disease remains stationary indefinitely, while in others it progresses very slowly. However, although rare, the disease may lead to a considerable loss of vision either by involving the macula or as a result of breaks in the outer or both retinal layers which lead to true retinal detachment. ${ }^{1891112}$ The expected rate of retinal detachment was found to be very low by Byer, ${ }^{10}$ while other authors considered the risk to be much higher. ${ }^{13-18}$

Correspondence to Dr Y. Yassur, Department of Ophthalmology, Soroka Medical Center, Bear-Sheba, Israel.
Although Byer claimed that it is rare for a patient with retinoschisis to experience visual field loss unless there is retinal detachment, ${ }^{10}$ others ${ }^{119}$ reported that, if the patient is carefully examined, retinoschisis is almost always involved with an irreversible absolute visual field defect, and this field defect increases as the retinoschisis progresses.

The management of senile retinoschisis is controversial, and there are many conflicting reports on the indications for appropriate treatment of this disorder. $^{78101214-1720-27}$ Straatsma and Foos ${ }^{7}$ claimed that treatment should be given only in selected cases where the macula is threatened by the progression of the retinoschisis, or when retinal breaks in both layers predispose or cause rhegmatogenous retinal detachment. Byer ${ }^{10}$ reached similar conclusions.

In the present study our indications for argon laser photocoagulation in retinoschisis are discussed and the results of our treatment reported.

\section{Patients and methods}

All the patients in the present study were treated at the Retinal Vascular Service at the Beilinson Medical Center during 1975-9. Fifty-seven eyes of 49 patients, 24 men and 25 women, aged between 52 to 77 years, were treated by argon laser photocoagulation. All the treated eyes had the clinical appearance of senile retinoschisis, either reticular or typical. However, sometimes it was difficult to classify them to fit these criteria, as they had clinical features of both types of retinoschisis. 
The argon laser treatment was performed from a few weeks to 11 years after the diagnosis of the retinoschisis was first made.

Of the treated eyes the argon laser treatment was performed on 12 , according to previously established indications. ${ }^{1012202324}$ These are: $(a)$ when the retinoschisis extended posteriorly more than 3 disc diameters (DD) from the macula (7 eyes); (b) when holes were present in the outer retinal layer (4 eyes); $(c)$ when holes were present in both retinal layers (1 eye).

The rest of the 45 eyes received treatment in accordance with indications which were laid by us as follows: (a) when the retinoschisis extended posteriorly $4 \mathrm{DD}$ or more from the ora serrata when first diagnosed, this being considered postequatorial; (b) when the retinoschisis progressed posteriorly to 4 DD or more from the ora serrata during the follow-up period.

The progression of the retinoschisis was recorded either by fundus drawings in relation to known landmarks or by successive Goldmann perimetric field examinations or both. $10 \%$ or more change in visual field defect was accepted as proving progression of the disease.

All the treated eyes had the argon laser photocoagulation for one to 3 sessions, in a similar mode to that described by l'Esperance ${ }^{23}$ and by Zweng and Little. ${ }^{24}$ The treatment was carried out with a power of $500-2000 \mu \mathrm{W}$, time duration of $0 \cdot 10-0 \cdot 50 \mathrm{~s}$ and with spot size of $200-1000 \mu \mathrm{W}$, depending on the proximity to the macula and the presence of pigmentation under the split retina. We aimed at achieving strong-intensity applications. The limitation posterior to the schisis ordinarly included a zone of about 2-3 $\mathrm{mm}$ of flat retina, unless the proximity to the macula allowed only a narrower zone of demarcation ( 3 eyes). In this way the schisis was demarcated and then covered by scattered applications of intense photocoagulation. Treatment was considered to be complete when this pattern was achieved.

The treated eyes were re-examined after a month and then at 6-month intervals up to 6 years, and for not less than 3 years, after photocoagulation. The examination consisted of tests of visual acuity, indirect ophthalmoscopy, Goldman perimetric visual field examination, 3-mirror contact lens examination, biomicroscopy, and measurement of intraocular pressure (IOP).

\section{Results}

In Table 1 the refraction of the treated eyes is presented; most of the eyes had mild hyperopia. In Table 2 the localisation of the maximum extent of the schisis is demonstrated: all the eyes had a temporal
Table 1 Refraction of the treated eyes

\begin{tabular}{lcll}
\hline & No. of eyes & $\begin{array}{l}2 \cdot 0 \\
\text { dioptres }\end{array}$ & $\begin{array}{l}2 \cdot 0 \\
\text { dioptres }\end{array}$ \\
\hline Emmetropes & $4 / 57$ & & \\
Myopes & $18 / 57$ & $12 / 18$ & $6 / 18$ \\
Hypermetropes & $35 / 57$ & $28 / 35$ & $7 / 35$ \\
\hline
\end{tabular}

Table 2 Quadrant of maximal involvement

\begin{tabular}{|c|c|}
\hline Quadrant & No. of eyes \\
\hline $\begin{array}{l}\text { Upper temporal } \\
\text { Lower temporal }\end{array}$ & $\begin{array}{l}15 / 57 \\
42 / 57\end{array}$ \\
\hline
\end{tabular}

retinoschisis, either upper or lower or both. It is worth noting that in 9 eyes the schisis occupied part of the lower nasal retina as well.

As shown in Table 3, the schisis was demarcated and completely collapsed in 11 out of 57 eyes and demarcated and partially collapsed in 37 more eyes. The schisis did not flatten but was demarcated in the remaining 9 eyes. In none of the treated eyes was there any progression of the schisis during the followup period. It is evident that eyes in which the schisis affected only one quadrant had a higher rate of complete collapse. In none of the eyes was there a retinal detachment during the follow-up period.

The visual acuity of the treated eyes during the follow-up period is shown in Table 4. Most of the patients kept the same visual acuity, and in those few who had a decline in their vision it was due to factors such as progression of senile cataract or change in refraction.

Choroidal haemorrhage during treatment was rare, and none of the patients had any major complication which could be attributed to the photocoagulation treatment, such as macular oedema, macular pucker, or preretinal fibrosis.

Table 3 Results of argon laser photocoagulation

\begin{tabular}{ll}
\hline Results & No. of eyes \\
\hline Schisis demarcated and completely collapsed & $11 / 57$ \\
Schisis demarcated and partially collapsed & $37 / 57$ \\
Schisis not flattened but demarcated & $9 / 57$ \\
Schisis progressing & $0 / 57$ \\
\hline
\end{tabular}

Table 4 Visual acuity of treated eyes

\begin{tabular}{lcc}
\hline Visual acuity & Initial (no. of eyes) & $\begin{array}{l}\text { Final }^{*} \\
\text { (no. of eyes) }\end{array}$ \\
\hline $6 / 6-6 / 15$ & $42 / 57$ & $35 / 57$ \\
$6 / 18-6 / 24$ & $9 / 57$ & $14 / 37$ \\
$6 / 30-6 / 60$ & $4 / 57$ & $4 / 57$ \\
$>6 / 60$ & $2 / 57$ & $4 / 57$ \\
\hline
\end{tabular}

${ }^{*}$ Decline in visual acuity was due to progression of senile cataracts. 


\section{Discussion}

Straatsma ${ }^{7}$ considered that the majority of eyes with degenerative retinoschisis 'remain free of main visual impairment.' It is true that many patients with retinoschisis remain asymptomatic and that retinal detachment is a rare complication. ${ }^{121}$ However, in various series one-third to two-thirds of the patients had symptoms, ${ }^{81317}$ and this cannot be underestimated even in the light of Byer's explanation as to the different sources of the patients studies. ${ }^{10}$

We have to consider the irreversible visual field damage which is caused by the progression of retinoschisis as unfavorable visual impairment. In contrast to Byer $^{10}$ and other authors ${ }^{14222526}$ it is our impression, as Sullivan and von Pirquet ${ }^{19}$ and DukeElder and Dobree ${ }^{1}$ pointed out, that in most patients with retinoschisis an absolute visual field defect can be found if carefully sought. We feel that the fact that in so many patients the schisis and the visual field defect at a certain time of examination do not progress does not mean that if the retinoschisis had been diagnosed earlier it could not be prevented from progressing. We were also aware of the anxiety laid upon patients in whom retinoschisis was already diagnosed, and of the difficulties of long follow-up of some of these elderly patients. Duke-Elder ${ }^{1}$ has already suggested that if the long-term results of photocoagulation are found to be good, treatment of this condition at an earlier stage may be justified.

In view of this opinion and of the lack of complications of argon laser treatment of retinoschisis reported earlier, ${ }^{23} 24$ and in view of our own previous experience, we extended the indications for laser treatment beyond those previously listed by others and included the following: (a) the extension of the retinoschisis posteriorly more than $4 \mathrm{DD}$ from the ora serrata when diagnosed; $(b)$ the progression of the retinoschisis posteriorly to $4 \mathrm{DD}$ or more from the ora serrata during the follow-up period. Fundus drawings correlated with landmarks, and $10^{\circ}$ or more change in visual field defect was accepted as proving progression of the disease.

The rationale for the mode of treatment was indicated by the nature of the disease and by its postulated pathogenesis ${ }^{117}$ and therefore included demarcation of the schisis and treatment of its entire area by strong photocoagulation application. The treatment is so performed in order to destroy a considerable bulk of pigment epithelium and photoreceptors and to create a firm scar reaching the inner plexiform layer, where the splitting process often takes place.

As our results show, the treatment caused either complete or partial collapse of the schisis in most of the treated eyes, it did not cause any progression of the schisis, and it caused no complication. It was much easier to evaluate the condition of the retinoschisis during the follow-up period, as the pigmented demarcating scars were easily visible on any fundus examination, even in the presence of moderately progressive cataract. There was also less need to rely on fundus drawings and on patients' co-operation during successive visual field tests, which are subject to wide variations even in intelligent patients. ${ }^{10}$ In elderly patients, in whom lens opacity progresses, it often also becomes difficult to assess over the years whether there are holes in the outer or in both retinal layers, and whether a localised true retinal detachment develops.

Taking into consideration the results of the treatment, which is a relatively uncomplicated outpatient procedure, the lack of long-term complications, and the simplified follow-up, we suggest that laser photocoagulation treatment for retinoschisis be performed at an earlier stage than is presently accepted, according to the additional indications that we have listed. This earlier treatment may prevent an unnecessary visual field loss as well as other possible complications of long-standing retinoschisis, which, although rare, are often difficult to evaluate when cataracts have progressed and when patients become older. It can also facilitate the follow-up by better visualisation of the demarcated, pigmented photocoagulation scars.

\section{References}

1 Duke-Elder S, Dobree JH. Diseases of the retina. In: DukeElder S, ed. System of Ophthalmology. St Louis: Mosby, 1967: 10: $559-68$.

2 Zimmerman LE, Spencer WH. The pathologic anatomy of retinoschisis, with a report of two cases diagnosed as malignant melanoma. Arch Ophthalmol 1960; 63: 10-9.

3 Zimmerman LE, Naumann G. The pathology of retinoschisis. In: McPherson A, ed. New and controversial aspects of retinal surgery. New York: Harper and Row, 1968: 400.

4 Hogan MJ, Zimmerman LE. Ophthalmic pathology. 2nd ed Philadelphia: Saunders, 1962: 550-4.

5 Spencer WH. Pathology of retinoschisis. Retinal diseases. Philadelphia: Lea and Fabiger, 1966: 185-9.

6 Foos RY. Senile retinoschisis-relationship to cystoid degeneration. Trans Am Acad Ophthalmol Otolaryngol 1970; 74: 33-51.

7 Straatsma BR, Foos RY. Typical and reticular degenerative retinoschisis. XXVI Francis I. Proctor Memorial Lecture. Am J Ophthalmol 1973; 75: 551-75.

8 Byer NE. Clinical study of senile retinoschisis. Arch Ophthalmol 1968; 79: 36-44.

9 Shea M, Schepens CL, von Pirquet SR. Retinoschisis, senile type, a clinical report of 107 cases. Arch Ophthalmol 1960; 63: 25-33.

10 Byer NE. The natural history of senile retinoschisis. Trans Am Acad Ophthalmol Otolaryngol 1976; 81: 458-71.

11 Zauberman $\mathrm{H}$, Ivry M. Retinoschisis and retinal detachment. $\mathrm{Br}$ J Ophthalmol 1969; 53: 127-30.

12 Okun E, Cibis PA. The role of photocoagulation in the management of retinoschisis. Arch Ophthalmol 1964; 72: 309-14. 
13 Pischel DK. Photocoagulation treatment of retinoschisis. Trans Ophthalmol Soc UK 1965; 85: 67-77.

14 Dobbie JG. Cryotherapy in the management of senile retinoschisis. Trans Am Acad Ophthalmol Otolaryngol 1969; 73: 1047-60.

15 Pischel DK. Surgical treatment of retinal cysts. Am J Ophthalmol 1963; 56: 1-16.

16 Okun E, Cibis PA. Retinoschisis: classification, diagnosis and management. In: McPherson A, ed. New and controversial aspects of retinal surgery. New York: Harper and Row, 1968; 424-34.

17 Harris GS. Retinoschisis: pathogenesis and treatment. Can J Ophthalmol 1968; 3: 312-7.

18 Hirsoe T, Marcil G, Schepens CL, et al. Acquired retinoschisis: observations and treatment. In: Pruett RC, Regen CDJ, eds. Retina congress. New York: Appleton-Century-Crofts, 1974: 489-504.

19 Sullivan GL, Von Pirquet SR. Retinoschisis: perimetry as a clue to diagnosis. Trans Am Ophthalmol Soc 1961; 59: 80-95.

20 Schepens CL. Present-day treatment of retinoschisis: an evalua- tion. In: McPherson A. New and controversial aspects of retinal surgery. New York: Harper and Row, 1968: 438-42.

21 Asayama R, Akutagawa T, Fukuchi S. Retinoschisis. Folia Ophthalmol Jpn 1968; 19: 539-42.

22 Belkin M, Oliver M. Surgical treatment of retinoschisis. Anatomical and functional results. Ann Ophthalmol 1973; 4: 598-601.

23 L'Esperance FA, Jr. Current diagnosis and management of chorioretinal diseases. St Louis: Mosby, 1977: 129-31.

24 Zweng HC, Little HL. Argon laser photocoagulation. St Louis: Mosby, 1977; 82-5.

25 Cox MS, Gutow RF. The treatment of breaks and detachment of the outer layer in degenerative retinoschisis. In: Pruett RC, Regan CDJ, eds. Retina congress. New York: Appleton-CenturyCrofts, 1972: 505-10.

26 Jesberg DO. Retinoschisis. Trans Pac Coast Otoophthalmol Soc 1966; 47: 145-55.

27 Brockhurst RJ. In: Dobbie JG. Cryotherapy in the management of senile retinoschisis. Trans Am Acad Ophthalmol Otolaryngol 1969; 73: 1047-60. 